\title{
Inactivation of Matrix-bound Matrix Metalloproteinases by Cross-linking Agents in Acid-etched Dentin
}

\author{
DLS Scheffel $\bullet J$ Hebling $\bullet$ RH Scheffel \\ K Agee $\bullet$ G Turco $\bullet$ CA de Souza Costa \\ D Pashley
}

\begin{abstract}
Clinical Relevance
Cross-linking agents used in clinically applicable periods of time are capable of inactivating matrix-bound matrix metalloproteinases (MMP) in demineralized dentin. Such treatment may render the hybrid layer less prone to degradation over time and produce long-lasting resin-dentin bonds.
\end{abstract}

\section{SUMMARY}

Objectives: Published transmission electron microscopy analysis of in vitro resin-dentin bonds shows that, after 44 months, almost 70\%

Debora Lopes Salles Scheffel, DDS, PhD student, Araraquara School of Dentistry, Sao Paulo, Brazil

Josimeri Hebling, DDS, PhD, FOAR UNESP, professor, Department of Orthodontics and Pediatric Dentistry, Rua Humaitá, Araraquara, Brazil

Regis Henke Scheffel, DDS, private practice, Sao Paulo, Brazil

Kelli Agee, BS, Laboratory Manager, Georgia Regents University, Augusta, GA, USA

Gianluca Turco, BS, PhD (Mechanical Engineering), School of Dentistry, University of Trieste, Trieste, Italy

Carlos de Souza Costa, DDS, PhD, professor and chair, Department of Oral Biology, Ararquara School of Dentistry, Sao Paulo, Brazil

*David Pashley, DMD, PhD, emeritus regents' professor, Department of Oral Biology, Georgia Regents University, College of Dental Medicine, Augusta, GA, USA

*Corresponding author: 1120 15th Street, CL2112, College of Dental Medicine, Augusta, GA 30912-1129, USA; e-mail: dpashley@gru.edu

DOI: $10.2341 / 12-425-\mathrm{L}$ of collagen fibrils from the hybrid layer disappear. Matrix metalloproteinases (MMPs) play an important role in that process and are thought to be the main factor responsible for the solubilization of dentin collagen. Therefore, this study aimed to evaluate the inactivation of matrix-bound MMPs by two different cross-linking agents, carbodiimide (EDC) or proanthocyanidin (PA), or the MMP-inhibitor, chlorhexidine (CHX), on acid-etched dentin using a simplified MMP assay method.

Materials and Methods: Dentin beams $(2 \times 1 \times 6$ $\mathrm{mm}$ ) were obtained from mid-coronal dentin of sound third molars and randomly divided into six groups $(G)$ according to the dentin treatment: G1: Deionized water (control); G2: 0.1 M EDC; G3: 0.5 M EDC; G4: 0.5 M EDC + 35\% hydroxyethyl methacrylate (HEMA); G5: 5\% PA; and G6: 2\% CHX. The beams were etched for 15 seconds with $37 \%$ phosphoric acid, rinsed, and then immersed for 60 seconds in one of the treatment solutions. The data were expressed both in absorbance values at $412 \mathrm{~nm}$ and in MMP-9 activity equivalents. The total MMP activity of dentin was analyzed for one 
hour by colorimetric assay (Sensolyte). Data were submitted to Wilcoxon nonparametric test and Mann-Whitney tests $(p>0.05)$.

Results: All experimental cross-linking solutions significantly reduced MMP activity from $\mathbf{7 9 . 8 \%}$ to $\mathbf{9 5 . 2 \%}$ when compared to the control group. No difference was observed among 0.1 M EDC (84.8\%), 5\% PA (87.6\%), and $2 \%$ CHX (79.8\%). Addition of 35\% HEMA to 0.5 M EDC produced inactivation $(95.2 \%)$ that was similar to that of 0.5 M EDC alone (92.7\%).

Conclusion: Dentin treatment with cross-linking agents is effective to significantly reduce MMP activity. Mixing 0.5 M EDC and 35\% HEMA did not influence EDC inhibitor potential.

\section{INTRODUCTION}

Since the introduction of the total-etching concept by Fusayama $^{1}$ in 1980 , the effects of acid-etching of dentin have been subject to many studies. Etching dentin with $32-37 \%$ phosphoric acid removes the mineral content of the top $10 \mu \mathrm{m}$ of dentin and exposes the collagen fibrils of the matrix, thereby creating space for monomer infiltration to achieve micromechanical retention of adhesive resins. ${ }^{2} \mathrm{Al}-$ though acid-etching of dentin provides satisfactory initial bond strength, those bond strengths fall over time, raising concerns about the long-term stability of adhesive-resin restorations. ${ }^{3}$

Resin/dentin bond degradation is a complex process that is not completely understood, involving the hydrolysis of both the resin and the collagen component of the hybrid layers. Acid-etched dentin contains bound matrix metalloproteinases (MMPs)$2,-3,-8,-9$, and -20 and cathepsins ${ }^{4,5}$ in their active forms. These enzymes are exposed and activated by acid-etching and can slowly degrade collagen fibrils ${ }^{6-9}$ within the hybrid layer, resulting in a significant bond strength loss of $36-70 \%$ between 12 and 14 months. ${ }^{10,11}$

In order to reduce the activity of these proteases and preserve the long-term integrity of adhesive interfaces, chlorhexidine (CHX) has been used as a nonspecific inhibitor of MMPs. ${ }^{6-9,11-13} \mathrm{CHX}$ is also an effective inhibitor of cysteine cathepsins. ${ }^{14}$ However, this substance is water-soluble and may undergo leaching from the hybrid layer, which impairs its long-term anti-MMP effectiveness. ${ }^{13}$

A new alternative to the inhibition of proteases by inhibitors is the treatment of demineralized dentin with cross-linking agents that can inactivate the catalytic site of these enzymes. ${ }^{15}$ The cross-linker 1 ethyl-3-[3-dimethylaminopropyl] carbodiimide (EDC) is capable of forming covalent peptide bonds between proteins by activating the free carboxyl groups of glutamic and aspartic acids present in protein molecules. ${ }^{16,17}$ This results in the formation of a o-acylisourea intermediate that reacts with the epsilon amino group of lysine or hydroxylysine in an adjacent polypeptide chain to form a stable, covalent amide bond. The only by-product of the reaction is urea ${ }^{18,19}$ which is water-soluble and easily removed from dentin by water rinsing. Furthermore, $0.5 \mathrm{M}$ EDC shows no transdentinal cytotoxicity on odontoblast-like cells (Scheffel and others, unpublished data) and is able to increase the mechanical properties of the collagen matrix. ${ }^{20}$

Other cross-linking agents, such as the proanthocyanidins (PAs), are polyphenolic natural products composed of flavan-3-ol subunits linked mainly through C4-C8 (or -C6) bonds. ${ }^{21}$ This substance is widely present in fruits, vegetables, nuts, seeds, flowers, and barks and shows numerous biological activities, such as antioxidant capacity, ${ }^{22}$ antimicrobial effects, ${ }^{23}$ anti-inflammatory properties, ${ }^{24}$ positive effects on cardiovascular diseases, ${ }^{25}$ and antiallergic activity. ${ }^{26}$

Thus, the purpose of this study was to evaluate the inactivation of matrix-bound MMPs by topical application of cross-linking agents on acid-etched dentin. The null hypothesis was that cross-linkertreated and -untreated dentin do not differ regarding MMP activity.

\section{MATERIALS AND METHODS}

Thirty extracted human third molars were obtained from 18-21-year-old patients with informed consent under a protocol approved by the Georgia Regents University. The teeth were stored frozen until required. After thawing, the enamel and superficial dentin were removed using an Isomet saw (Buehler Ltd, Lake Bluff, IL, USA) under water cooling. One 1-mm-thick dentin disk was produced from the midcoronal dentin of each tooth. Then 60 dentin beams $(2 \times 1 \times 6 \mathrm{~mm})$ were sectioned from the dentin disks. One such beam was placed in each well. This represents $40 \mathrm{~mm}^{2}$ of dentin, which is equivalent to a Class I cavity prepared in a mandibular first molar 2 $\mathrm{mm}$ into the dentin and $3 \times 4 \mathrm{~mm}$ in dimension. The beams were etched by dipping them into $37 \%$ phosphoric acid $(\mathrm{pH},-0.5)$ for 15 seconds and then copiously rinsing with deionized water for 15 seconds. The beams were randomly divided into six groups $(n=10)$ according to the dentin treatment, as 
follows: G1: Deionized water (positive control) ( $\mathrm{pH}$ 6.73); G2: 0.1 M EDC (pH 6.07); G3: 0.5 M EDC (pH 6.24); G4: 35 vol\% hydroxyethyl methacrylate (HEMA) in water + 0.5 M EDC (pH 6.34); G5: 5\% PA (Polyphenolics Inc, Madera, CA, USA) ( $\mathrm{pH}$ 5.2) in phosphate-buffered saline ( $\mathrm{pH} 6.0$ ); and G6: 2 vol\% CHX digluconate (negative control) in water $(\mathrm{pH}$ 6.43). All beams were dipped in the treatment solutions for 60 seconds and rinsed with distilled water for 10 seconds, except for $2 \%$ CHX, in which case the beams were only blot dried. After the treatment, each beam was placed in a $200 \mu \mathrm{L} /$ well containing generic MMP substrate (Sensolyte Generic MMP colorimetric assay kit; catalog No. 72095, AnaSpec Inc, Fremont, CA, USA) for 60 minutes at $25^{\circ} \mathrm{C}$ in a 96 -well plate. At the end of 60 minutes, the total MMP activity was determined by measuring the absorbance of the wells at $412 \mathrm{~nm}$ in a plate reader (Synergy HT microplate reader, BioTek Instruments, Winooski, VT, USA) against appropriate blanks. All chemicals were purchased from Sigma/Aldrich Chemical Co. The generic MMP assay uses a proprietary thiopeptide to assay MMP-1, -2, $-3,-7,-8,-9,-12,-13$, and -14 . Thus, the kit measured the total endogenous MMP activity of dentin, with the exception of MMP-20 (enamelysin). A standard curve of absorbance of the substrate vs rh MMP-9 activity (ng) was constructed to permit expression of total MMP activity in MMP-9 equivalents. The rh MMP-9 was activated using trypsin at a final concentration of $10 \mu \mathrm{g} / \mathrm{mL}, \mathrm{pH} 7.4$, at $37^{\circ} \mathrm{C}$ for two hours. Then the trypsin was inactivated by addition of trypsin inhibitor at a final concentration of $100 \mu \mathrm{g} /$ mL. Human recombinant MMP-9 was purchased from Calbiochem (catalog No. PF038; Billerica, MA, USA). Its specific activity was 1300 pmoles/mg.

\section{Statistical Analysis}

For determination of MMP activity, the absorbance data set was submitted to Wilcoxon nonparametric test and Mann-Whitney test at the 5\% level of significance. The percentage of MMP activity inhibition was calculated based on the water control group MMP activity and MMP-9 equivalents (ng/ well) based on the rh MMP-9 curve.

\section{RESULTS}

When mineralized dentin beams were dipped in 37 wt\% phosphoric acid for 15 seconds and then rinsed with water, the top $8-10 \mu \mathrm{m}$ of the beams were completely demineralized (Figure 1). When etched dentin beams were dipped in water (control) and then dropped into the generic MMP substrate, the
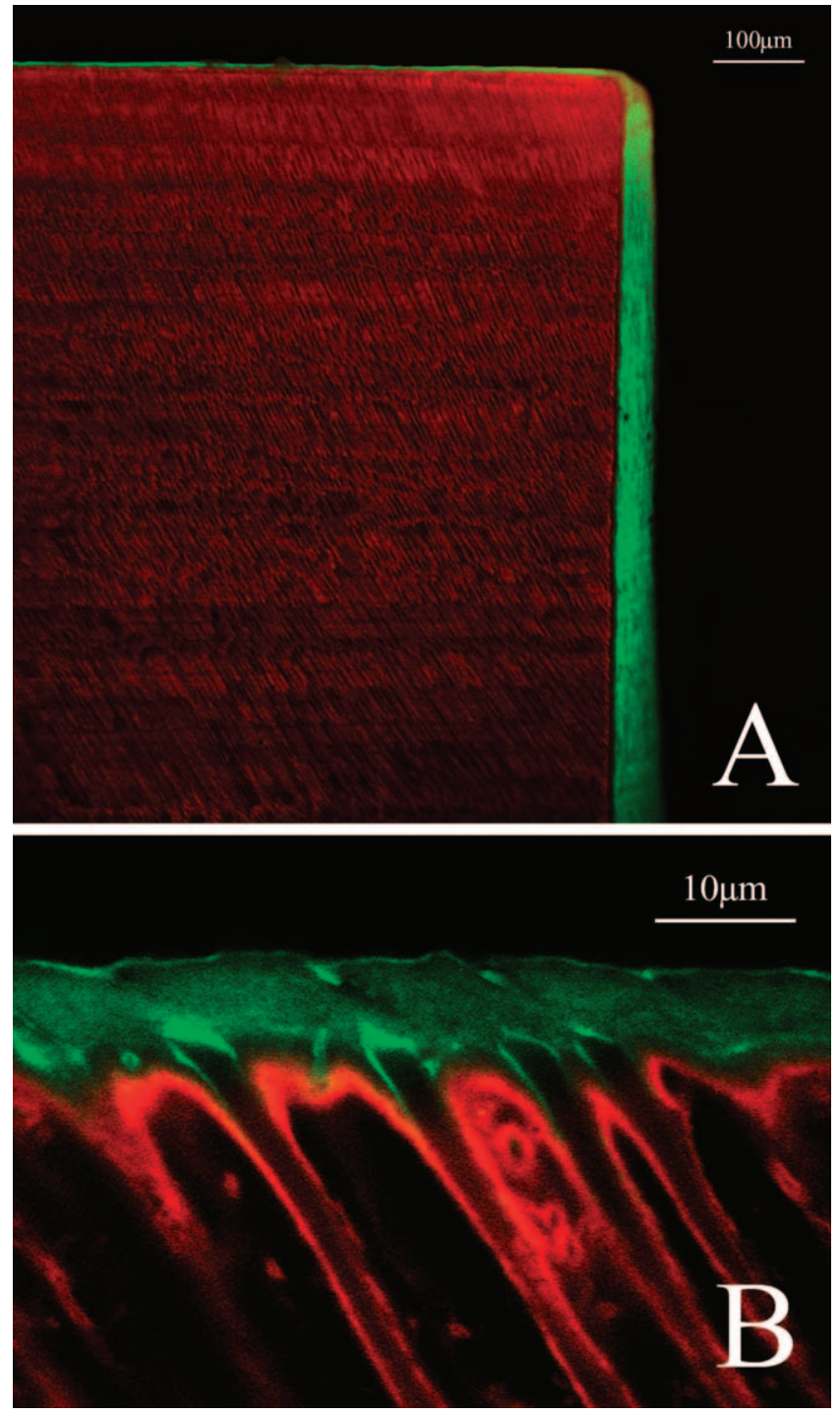

Figure 1. Confocal laser scanning microscope (CLSM) images of the etched layer shown dyed green on the surface of a dentin beam. Dentin beams were etched in 37\% phosphoric acid for 15 seconds and then rinsed with deionized water for 60 seconds and labeled for five hours, respectively, with $1 \%$ w/v fluorescein isothiocyanate (FITC) in anhydrous dimethyl sulfoxide (DMSO) and $1 \% \mathrm{w} / \mathrm{v}$ xylenol orange (XO) in water. The two fluorochromes selectively label collagen (FITC) and the mineralized matrix (XO), respectively. Prior to CLSM observation, the slabs were rapidly blotted with absorbent paper to remove the excess of fluorochrome, mounted on glass slides, and promptly examined. Samples were scanned in two-channel fluorescence mode with both $488 \mathrm{~nm}$ excitation-525 nm emission (green channel) and $546 \mathrm{~nm}$ excitation-580 nm emission (red channel), respectively, for FITC and XO labeling. (A) 10X projection of 53 images (final Z-stack thickness: $346 \mu \mathrm{m}$ ); the sample was intentionally tilted to highlight the peripheral distribution of demineralized collagen. (B) 100x image of the border between demineralized surface collagen fibrils (etched layer) and underlying mineralized dentin matrix.

absorbance at $412 \mathrm{~nm}$ gradually increased to 0.51 $( \pm 0.138)$ over 60 minutes. That value was considered to represent $100 \%$ of the total MMP activity in the etched dentin, and it was used to calculate the 


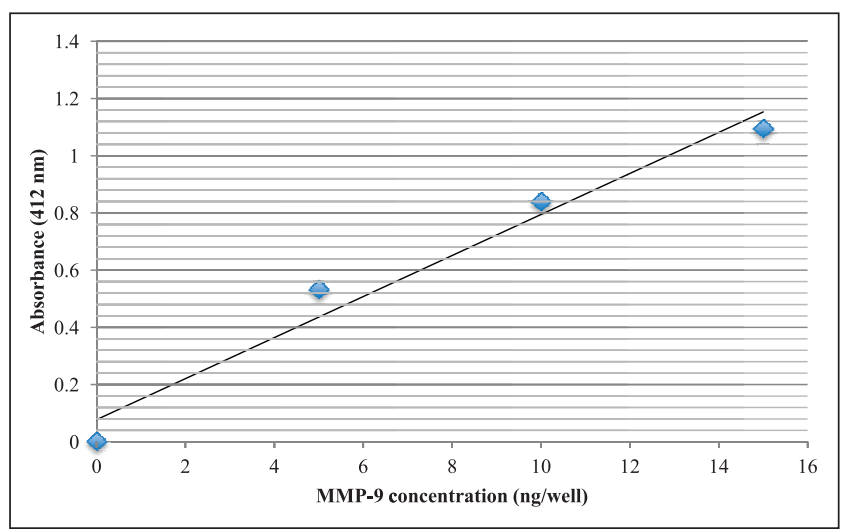

Figure 2. Standard curve of rh matrix metalloproteinase (MMP)-9 activity (ng/well) vs absorbance at $412 \mathrm{~nm}$ after 60 minutes.

percentage of MMP activity inhibition of the investigated cross-linking agents and CHX. A standard curve of substrate absorbance at 60 minutes vs ng of rh MMP-9 is shown in Figure 2. All cross-linking agents significantly reduced MMP activity in acidetched dentin after 60 seconds of topical treatment (Table 1). The percentage of MMP inhibition for the EDC solutions, PA, and CHX ranged from $79.8 \%$ for 2 wt\% CHX to $95.2 \%$ for $0.5 \mathrm{M} \mathrm{EDC} \mathrm{+} \mathrm{35 \%} \mathrm{HEMA}$ (Table 1). There was no statistical difference in MMP activity when $0.1 \mathrm{M} \mathrm{EDC,} 5 \% \mathrm{PA}$, and $2 \% \mathrm{CHX}$ were compared (Table 1). When 0.5 M EDC was mixed with 35\% HEMA to simulate the composition of an adhesive primer, the HEMA did not interfere with that cross-linker in inactivating the total MMP activity of acid-etched dentin. When the absorbances of the MMP activity of acid-etched dentin were expressed in MMP-9 activity equivalents, the total MMP activity of acid-etched dentin was equivalent to $6.10( \pm 1.93) \mathrm{ng}$ of MMP-9 per $2 \times 1 \times 6 \mathrm{~mm}$ of acidetched dentin.

\section{DISCUSSION}

The conventional method for analyzing the total bound MMP activity using Sensolyte Generic MMP colorimetric assay kit includes the complete demineralization of dentin beams for 18 hours with $10 \%$ phosphoric acid. ${ }^{27}$ The current study used a simplified MMP assay method in which the dentin was acid-etched for 15 seconds with $37 \%$ phosphoric acid. That avoids the complete dentin demineralization and reproduces more closely the surface demineralization of dentin that is completed during etch-andrinse bonding procedures. The complete demineralization of the dentin beam creates a much deeper collagen area $(2 \times 1 \times 6 \mathrm{~mm})$ to be infiltrated by the cross-linking solutions and adhesive resins. Clinically, acid-etching of dentin by $37 \mathrm{wt} \%$ phosphoric acid for 15 seconds only demineralizes dentin to a depth of 8-10 $\mu \mathrm{m}$ (Figure 1). Such relatively thin zones of demineralized dentin are easily saturated by test solutions within seconds. Nevertheless, this technique does not reproduce all in vivo conditions, such as the presence of pulpal pressure and the outflow of dentinal fluid.

The hybrid layer is composed of 30 vol\% collagen $^{28}$ (primarily type I), while the other $70 \%$ corresponds to resin and residual solvent. ${ }^{2}$ The collagen fibril network acts as an anchorage to resin, enabling the retention of adhesive restorations. However, transmission electron microscopy analyses revealed that almost $70 \%$ of collagen from the adhesive interface disappears after 44 months of water storage. ${ }^{29}$ Proteases such as metalloproteinases (MMPs) and cysteine cathepsins are thought to be responsible for collagen fibril enzymatic degradation via hydrolysis. ${ }^{30}$

Exogenous MMP inhibitors have been tested in order to reduce protease activity and prolong the durability of resin-dentin bonds. CHX was the first

Table 1: Absorbance, Percent Inactivation/Inhibition of Total Matrix-bound Matrix Metalloproteinase (MMP) Activity in Dentin, and MMP-9 equivalent (ng/dentin beam) ${ }^{1}$

\begin{tabular}{|c|c|c|c|}
\hline Demineralized Dentin Treatment & Absorbance $(412 \mathrm{~nm})$ & MMP Inhibition, \% & MMP-9 Equivalent, ng \\
\hline Water (control) & $0.515( \pm 0.138) \mathrm{A}$ & $0 \mathrm{D}$ & $6.10( \pm 1.93) \mathrm{A}$ \\
\hline $0.5 \mathrm{M}$ EDC & $0.038( \pm 0.014) \mathrm{CD}$ & $92.7( \pm 2.6)$ АВ & $0( \pm 0.19) \mathrm{CD}$ \\
\hline 0.5 M EDC + 35\% HEMA & $0.025( \pm 0.016) \mathrm{D}$ & $95.2( \pm 3.0)$ A & $0( \pm 0.22) \mathrm{D}$ \\
\hline $0.1 \mathrm{M}$ EDC & $0.078( \pm 0.042) \mathrm{BC}$ & $84.8( \pm 8.2) \mathrm{BC}$ & $0( \pm 0.59) \mathrm{BC}$ \\
\hline $5 \% \mathrm{PA}$ & $0.064( \pm 0.035) \mathrm{BC}$ & $87.6( \pm 6.7) \mathrm{BC}$ & $0( \pm 0.49) \mathrm{BC}$ \\
\hline $2 \% \mathrm{CHX}$ & $0.104( \pm 0.031)$ в & $79.8( \pm 6.0) c$ & $0.37( \pm 0.43)$ в \\
\hline
\end{tabular}


MMP inhibitor proposed for such a purpose during bonding to dentin. ${ }^{31}$ It has been largely studied as a nonspecific $\mathrm{MMP}^{12}$ and cathepsin inhibitor. ${ }^{14} \mathrm{CHX}$ adsorbs on dentin and decreases hybrid layer degradation in vitro ${ }^{7,32-34}$ and in vivo..$^{6,8,11,13}$ However, this inhibitor is soluble in water and can slowly leach from the adhesive interface over time,${ }^{13}$ since no chemical bond is established between the CHX molecule and the collagen fibril.

One of the mechanisms proposed to explain how MMPs degrade collagen is that these proteases unwind collagen molecules when they bind to them. By doing that, the endogenous protease's active site is allowed sufficient space to attack the specific glycine-isoleucine peptide bond in peptide chains. ${ }^{35-}$ ${ }^{37}$ Cross-linking agents stiffen collagen polypeptides so that they cannot unwind, and they can also inactivate the catalytic site of proteases ${ }^{38}$ by creating a new peptide bond across adjacent peptides. Hence, it is reasonable to expect that MMP inactivation by cross-linking agents should last much longer than the inhibition of proteases by matrix-bound CHX. EDC and PA were first used to increase the modulus of elasticity of collagen and make it more difficult for MMPs to unwind the collagen triple-helix structure. However, EDC and PA are still not capable of increasing the stiffness of collagen in clinically relevant periods of times, such as 30 seconds and 60 seconds (Scheffel and others, unpublished data).

Despite the long application times that crosslinking agents require to increase collagen stiffness, ${ }^{20}$ they are effective against MMPs in 60 seconds. The results of this study require rejection of the tested null hypothesis. All investigated solutions significantly decreased MMP activity in acid-etched dentin within 60 seconds. Five percent PA, 0.1 M EDC, and 0.5 M EDC were all able to inactivate more than $84 \%$ of the total active MMPs. EDC activates the free carboxylic acid groups of glutamic and aspartic acids without introducing additional methylene groups. MMPs-2 (EC 3.4.24.24), -8 (EC 3.4.24.34), -9 (EC 3.4.24.35), and -20 (EC 3.4.24), the MMPs reported to be in dentin matrix, have glutamic acid in their active sites in positions 404, 218, 402, and 227, respectively, allowing EDC to react to those sites. Additionally, the concentrations of EDC tested in this study did not produce any evidence of transdentinal cytotoxic effect on odontoblast-like cells in separate experiments (Scheffel and others, unpublished data), where they were also used at $0.1 \mathrm{M}$ and $0.5 \mathrm{M}$, making EDC safe for in vivo application. The use of $0.5 \mathrm{M}$ EDC was designed to accelerate its rate of diffusion into demineralized dentin. That EDC concentration is far in excess of the amount of protein in demineralized dentin. It is likely that only $1-2 \%$ of the EDC could react with proteins in 60 seconds. This would only generate $0.005-0.01 \mathrm{M}$ of urea, which is not sufficient to denature any proteins. Denaturing concentrations of urea require 2-8 M. ${ }^{39,40}$

PA is a natural plant cross-linking agent. The mechanism of cross-linking is not completely understood. There are four different theories to explain how PA interacts with proteins. They include covalent, ${ }^{41}$ ionic, ${ }^{42}$ hydrogen bonding ${ }^{43}$ and hydrophobic interactions. ${ }^{44}$ This substance has been reported to increase the stiffness of demineralized dentin ${ }^{45}$ and to inhibit the progression of artificial root caries. ${ }^{46,47}$ Additionally, scanning electron microscopy of demineralized dentin collagen treated with $15 \%$ PA for periods shorter than 120 seconds showed a homogeneous and regular collagen fibril arrangement, regardless of the surface moisture condition. ${ }^{38}$ That result indicates that, in addition to acting as MMP inhibitor cross-linking agents, it can stiffen demineralized dentin sufficiently to minimize the risk of collagen network collapse resulting from air-drying. However, the PA solution has a dark color, which stains the dentin despite water rinsing. That could be a drawback for the clinical use of this cross-linker. Its rapid, complete inactivation of matrix-bound MMPs in dentin indicates that more research should be done to try to isolate an uncolored fraction of the PA.

When 0.5 M EDC was solubilized in 35 vol\% HEMA, there was no reduction in its ability to inactivate all of the MMPs in dentin. That is, it was as effective as 0.5 M EDC alone. Since HEMA is an important component of adhesives, it may be possible to mix EDC with HEMA and other primer components in etch-and-rinse adhesive systems to inactivate MMPs during bonding. However, it is not known whether EDC influences adhesive polymerization. Further studies are still needed to demonstrate the effects of short-time application of crosslinking agents over time in vitro and in vivo.

\section{CONCLUSIONS}

Dentin treatment with cross-linking agents is effective in significantly reducing MMP activity; $0.5 \mathrm{M}$ EDC showed the best results. Mixing 0.5 M EDC and $35 \%$ HEMA did not influence EDC cross-linking of MMPs, indicating that EDC could be added to primers in adhesive systems. 


\section{Acknowledgements}

This study was supported, in part, by R01 DE015306 from the NIDCR (PI. David H. Pashley) and CNPq No. 305204/2010-6 and FAPESP 2012/08866-4 (PI. Josimeri Hebling). The authors are grateful to Mrs. Michelle Barnes for her secretarial support.

\section{Conflict of Interest}

The authors of this manuscript certify that they have no proprietary, financial, or other personal interest of any nature or kind in any product, service, and/or company that is presented in this article.

(Accepted 1 April 2013)

\section{REFERENCES}

1. Fusayama T (1980) New adhesive resin restoration. In: New Concepts in Operative Dentistry Quintessence Publishing, Chicago 61-156.

2. Nakabayashi N, \& Pashley DH (1998) Evolution of dentin-resin bonding In: Hybridization of Dental Hard Tissues Quintessence Publishing, Chicago 1-20.

3. Reis AF, Giannini M, \& Pereira PNR (2008) Effects of a peripheral enamel bond on the long term effectiveness of dentin bonding agents exposed to water in vitro Journal Biomedical Materials Research Part B Applied Biomaterials 85(1) 10-17.

4. Zhang S-C, \& Kern M (2009) The role of host-derived dentinal matrix metalloproteinases in reducing dentin bonding of resin adhesives International Journal of Oral Science 1(4) 163-176.

5. Tersariol IL, Geraldeli S, Minciotti CL, Nascimento FD, Pääkkönen V, Martins MT, Carrilho MR, Pashley DH, Tay FR, Salo T, \& Tjäderhane L (2010) Cysteine cathepsins in human dentin-pulp complex Journal of Endodontics 36(3) 475-481.

6. Hebling J, Pashley DH, Tjäderhane L, \& Tay FR (2005) Chlorhexidine arrests subclinical degradation of dentin hybrid layers in vivo Journal of Dental Research 84(8) 741-746.

7. Carrilho MR, Carvalho RM, De Goes MF, Di Hipolito V, Geraldeli S, Tay FR, Pashley DH, \& Tjäderhane L (2007) Chlorhexidine preserves dentin bond in vitro Journal of Dental Research 86(1) 90-94.

8. Brackett WW, Tay FR, Brackett MG, Dib A, Sword RJ, \& Pashley DH (2007) The effect of chlorhexidine on dentin hybrid layers in vivo Operative Dentistry 32(2) 107-111.

9. Brackett MG, Tay FR, Brackett WW, Dip A, Dipp FA, Mai S, \& Pashley DH (2009) In vivo chlorhexidine stabilization of an acetone-based dentin adhesives Operative Dentistry 34(4) 381-385.

10. Koshiro K, Inoue S, Tanaka T, Koase K, Fujita M, Hashimoto M, \& Sano H (2004) In vivo degradation of resin-dentin bonds produced by a self-etch vs. a total-etch adhesive system European Journal of Oral Sciences 112(4) $368-375$.

11. Carrilho MRO, Geraldeli S, Tay FR, de Goes MF, Carvalho RM, Tjäderhane L, Reis AF, Hebling J, Mazzoni A, Breschi L, \& Pashley DH (2007) In vivo preservation of the hybrid layer by chlorhexidine Journal of Dental Research 86(6) 529-533.

12. Gendron R, Grenier D, Sorsa T, \& Mayrand D (1999) Inhibition of the activities of matrix metalloproteinases 2 , 8 , and 9 by chlorhexidine Clinical Diagnosis and Laboratory Immunology 6(3) 437-439.

13. Ricci HA, Sanabe ME, de Souza Costa CA, Pashley DH, \& Hebling J (2010) Chlorhexidine increases the longevity of in vivo resin-dentin bonds European Journal of Oral Sciences 118(4) 411-416.

14. Scaffa PM, Vidal CM, Barros N, Gesteira TF, Carmona AK, Breschi L, Pashley DH, Tjäderhane L, Tersariol IL, Nascimento FD, \& Carrilho MR (2012) Chlorhexidine inhibits the activity of dental cysteine cathepsins Journal of Dental Research 91(4) 420-425.

15. Liu R, Fang M, Xiao Y, Li F, Yu L, Zhao S, Shen L, \& Chen J (2011) The effect of transient proanthocyanidins preconditioning on the cross-linking and mechanical properties of demineralized dentin Journal of Materials Science Materials in Medicine 22(11) 2403-2411.

16. Timkovich R (1977) Detection of the stable addition of carbodiimide to proteins Analytical Biochemistry 79(1-2) 135-143.

17. Zeeman R, Dijkstra PJ, van Wachem PB, van Luyn MJ, Hendriks M, Cahalan PT, \& Feijen J (1999) Successive epoxy and carbodiimide cross-linking of dermal sheep collagen Biomaterials 20(10) 921-931.

18. Olde Damink LH, Dijkstra PJ, van Luyn MJ, van Wachem PB, Nieuwenhuis P, \& Feijen J (1996) In vitro degradation of dermal sheep collagen cross-linked using a water-soluble carbodiimide Biomaterials 17(7) 679-684.

19. Olde Damink LH, Dijkstra PJ, van Luyn MJ, van Wachem PB, Nieuwenhuis P, \& Feijen J (1996) Crosslinking of dermal sheep collagen using a water-soluble carbodiimide Biomaterials 17(7) 765-773.

20. Bedran-Russo AK, Vidal CM, Dos Santos PH, \& Castellan CS (2010) Long-term effect of carbodiimide on dentin matrix and resin-dentin bonds Journal of Biomedical Materials Research Part B Applied Biomaterials 94(1) 250-255.

21. Kennedy JA, \& Taylor AW (2003) Analysis of proanthocyanidins by high-performance gel permeation chromatography Journal of Chromatography A 995(1-2) 99-107.

22. Bors W, Michel C, \& Stettmaier K (2000) Electron paramagnetic resonance studies of radical species of proanthocyanidins and gallate esters Archives of Biochemical and Biophysics 374(2) 347-355.

23. Cowan MM (1999) Plant products as antimicrobial agents Clinical Microbiological Review 12(4) 564-582.

24. Scalbert A, Déprez S, Mila I, Albrecht AM, Huneau JF, \& Rabot S (2000) Proanthocyanidins and human health: Systemic effects and local effects in the gut Biofactors 13(1-4) 115-120.

25. Teissedre PL, Frankel EN, Waterhouse AL, Peleg H, \& German JB (1996) Inhibition of in vitro human LDL oxidation by phenolic antioxidants from grapes and wines Journal of Science Food Agriculture 70(1) 55-61. 
26. Bagchi D, Bagchi M, Stohs SJ, Das DK, Ray SD, Kuszynski CA, Joshi SS, \& Pruess HG (2000) Free radicals and grape seed proanthocyanidin extract: Importance in human health and disease prevention Toxicology 148(2-3) 187-197.

27. Tezvergil-Mutluay A, Agee KA, Hoshika T, Tay FR, \& Pashley DH (2010) The inhibitory effect of polyvinylphosphonic acid on functional matrix metalloproteinase activities in human demineralized dentin Acta Biomaterialia 6(10) 4136-4142.

28. Pashley DH, Tay FR, Breschi L, Tjäderhane L, Carvalho RM, Carrilho M, \& Tezvergil- Mutluay A (2011) State of the art etch-and-rinse adhesives Dental Materials 27(1) 1-16.

29. Armstrong SR, Vargas MA, Chung I, Pashley DH, Campbell JA, Laffoon JE, \& Qien F (2004) Resin-dentin interfacial ultrastructure and microtensile dentin bond strength after five-year water storage Operative Dentistry 29(6) 705-712.

30. Tjäderhane L, Nascimento FD, Breschi L, Mazzoni A, Tersarial ILS, Geraldeli S, Tezvergil-Mutluay A, Carrilho M, Carvalho RM, Tay FR, \& Pashley DH (2013) Optimizing dentin bond durability: Control of collagen degradation by matrix metalloproteinases and cysteine cathepsines Dental Materials 29(1) 116-135.

31. Pashley DH, Tay FR, Yiu C, Hashimoto M, Breschi L, Carvalho RM, \& Ito S (2004) Collagen degradation by host-derived enzymes during aging Journal of Dental Research 83(3) 216-221.

32. Campos EA, Correr GM, Leonardi DP, Barato-Filho F, Gonzaga CC, \& Zielak JC (2009) Chlorhexidine diminishes the loss of bond strength over time under simulated pulpal pressure and thermo-mechanical stressing Journal of Dentistry 37(2) 108-114.

33. Komori PC, Pashley DH, Tjäderhane L, Breschi L, Mazzoni A, De Goes MF, Wang L, \& Carrilho MR (2009) Effect of $2 \%$ chlorhexidine digluconate on the bond strength to normal versus caries-affected dentin Operative Dentistry 34(2) 157-165.

34. Breschi L, Mazzoni A, Nato F, Carrilho M, Visintini E, Tjäderhane L, Ruggeri A Jr, Tay FR, Dorigo ED, \& Pashley DH (2010) Chlorhexidine stabilizes the adhesive interface: A 2-year in vitro study Dental Materials 26(4) 320-325.

35. Chung L, Dinakarpandian D, Yoshida N, Lauer-Fields JL, Fields GB, Visse R, \& Nagase H (2004) Collagenase unwinds triple-helical collagen prior to peptide bond hydrolysis EMBO Journal 23(15) 3020-3030.
36. Gioia M, Monaco S, Fasciglione GF, Coletti A, Modesti A, Marini S, \& Coletta M (2007) Characterization of the mechanisms by which gelatinase $\mathrm{A}$, neutrophil collagenase, and membrane-type metalloproteinase MMP-14 recognize collagen I and enzymatically process the two alpha-chains Journal of Molecular Biology 368(4) 1101-1113.

37. Nagase H, \& Fushimi K (2008) Elucidating the function of non-catalytic domains of collagenases and aggrecanases Connective Tissue Research 49(3) 169-174.

38. Liu Y, Tjäderhane L, Breschi L, Mazzoni A, Li N, Mao J, Pashley DH, \& Tay FR (2011) Limitations in bonding to dentin and experimental strategies to prevent bond degradation Journal of Dental Research 90(8) 953-968.

39. Bennion BJ, \& Daggett V (2003) The molecular basis for the chemical denaturation of proteins by urea Proceedings of the National Academy of Sciences 100(9) 5142-5147.

40. Canchi DR, Paschek D, \& García AE (2010) Equilibrium study of protein denaturation by urea Journal of the American Chemical Society 132(7) 2338-2344.

41. Pierpoint WS (1969) O-Quinones formed in plant extracts: Their reactions with amino acids and peptides Biochemical Journal 112(5) 609-616.

42. Loomis WD (1974) Overcoming problems of phenolics and quinines in the isolation of plant enzymes and organelles Methods in Enzymology 31 528-544.

43. Ku CS, Sathishkumar M, \& Mun SP (2007) Binding affinity of proanthocyanidin from waste Pinus radiata bark onto proline-rich bovine Achilles tendon collagen type I Chemosphere 67(8) 1618-1627.

44. Han B, Jaurequi J, Tang BW, \& Nimni ME (2003) Proanthocyanidin: A natural crosslinking reagent for stabilizing collagen matrices Journal of Biomedical Materials Research Part A 65(1) 118-124.

45. Bedran-Russo AK, Pashley DH, Agee K, Drummond JL, \& Miescke KJ (2008) Changes in stiffness of demineralized dentin following application of collagen crosslinkers Journal of Biomedical Materials Research Part B Applied Biomaterials 86(2) 330-334.

46. Xie Q, Bedran-Russo AK, \& Wu CD (2008) In vitro remineralization effects of grape seed extract on artificial root caries Journal of Dentistry 36(11) 900-906.

47. Walter R, Miguez PA, Arnold RR, Pereira PN, Duarte WR, \& Yamauchi M (2008) Effects of natural cross-linkers on the stability of dentin collagen and the inhibition of root caries in vitro Caries Research 42(2) 263-268. 